\title{
CHAPTER 90
}

\section{PLUNGING WAVE PRESSURES ON A SEMI-CYLINDRICAL TUBE}

\author{
by \\ Yuan Jen, Assistant Professor \\ Pang-Mou Lin, Graduate Student \\ Department of Coastal and Oceanographlc Englneering \\ University of Florıda-Gainesville, Florida \\ USA
}

\begin{abstract}
Laboratory tests were made on a 6-1nch diameter semi-cylindrical tube simulating a prototype concrete structure designed to be placed parallel to the coastline in the surf zone to intercept of fshore transport of beach materials and thus preserving the beach The model beach was of fixed bed type with a slope of 1 to 15 The crest elevation of the tube was set at the still water level for most of the test runs and the sloping beach intersected a flat channel bottom at a depth of $2075^{\prime \prime}$
\end{abstract}

The test parameters used may be summarized as follows

$$
\begin{aligned}
\mathrm{H} / \mathrm{L} & =0005 \text { to } 0052 \\
\mathrm{~d} / \mathrm{L}_{\mathrm{O}} & =0027 \text { to } 0111 \\
\mathrm{H} / \mathrm{D}= & 026 \text { to } 118
\end{aligned}
$$

where $\mathrm{H}$ is the wave height measured at the toe of the beach, $\mathrm{d}$ is the water depth In the flat portion of the channel, $D$ is the tube diameter, $L$ is the wave length in the flat channel and $L_{0}$ is the equivalent deep water wave length

The above test conditions resulted in plunging breakers on the beach except for a few test cases

Pressure measurements were made around the tube circumference, at an interval of 30 degrees azımuth angle, by using a high frequency response pressure transducer It was found that the pressure distribution could be treated in two parts

Part I During the wave uprush, an impact pressure of short duration was recorded at the front of the tube, followed by smoother pressure varlations in time

Part II During the wave downrush, the volume of water transported across the tube flowed back under gravity The pressure distribution on the beach side of the tube was relatively steady during the flow reversing process 
Solitary wave theory was used to compute the breaking wave height and wave celerity The validity of analytical treatments were evaluated by comparison of measured and observed data The impact pressures at the front of the tube occurred in somewhat random nature The average impact pressure in dimensionless form $\mathrm{P}_{1} / \gamma \mathrm{H}$ was found dependent upon wave steepness The maximum lmpact pressure decreases as the plunging wave steepness increases Waves with $H / L<0$ exert little impact The impulse-momentum theory was applied to investigate the behavio of impact pressures The pressure distribution on the tube surface during the wave downrush was treated as quasi-steady case in which the Bernoulli princlple for steady state condition applies

\section{INTRODUCTION}

The phenomenon of wave and structure interaction has long been a subject of vital interest to coastal engineers Considerable information related to the forces acting on coastal structures due to the action of non-breaking waves can be found in the engineering literature, and dependable methods of predicting wave forces are available However, despite the fact that a large number of published works also deal with breaking waves, few conclusions can be drawn in order to establish confidence in the design of coastal structures to be located in the surf zone Analytical means of evaluating wave-structure interactions in the surf zone are difficult to derive because

1 Presently available wave theories are inadequate in describing the wave characteristics in the surf zone

2 Forces or pressures exerted by traveling breakers differ in magnitude from wave to wave, therefore the analysis of such forces must rely upon statistical means

The Coastal Engineering Laboratory, University of Florida, conducted a two phase study on a semi-cylindrical concrete tube structure, designed to be placed parallel to the beach at or near the mean water line to intercept the offshore transport of beach materials The study includes

\footnotetext{
Phase I - Movable Bed Model Study - To evaluate the stability of the structure under wave action.

Phase II - Fixed Bed Model Study - To measure the pressure distrubution around the tube surface and to determin the wave loading
}

Only the results of Phase II will be presented in this paper, since the results of Phase I are mannly qualitative in nature The effectiveness of the structure in trapping beach materials is beyond the scope of this paper

\section{MODEL SET-UP AND INSTRUMENTATION}

The model study on wave pressures was performed in a $100 \mathrm{ft} x 10 \mathrm{ft} x$ $25 \mathrm{ft}$ wave channel A semi-cylindrical tube, 6 inches in diameter, was mounted on a fixed slope of 1 to 15 at a distance of 85 feet from the wave generator (see Figure 1) The water depths were 175 inches at low water and 2075 inches a 
high water The high water represents a case when the tube is barely submerged and most test runs were conducted at this water level Variable wave heights and periods were recorded by a parallel wire resistance-type wave gage located 22 feet in front of the test structure at the point where the channe1 bottom starts to flatten out A high sensitivity pressure transducer was mounted on a circular test section which was free to rotate about its center so that the pressure sensor could be moved to any desired location along the tube circumference When performing the tests, the transducer was rotated at every $30^{\circ}$ interval and the same test condition was repeated for every transducer position The records showed that the wave inputs could be accurately reproduced and the pressure response at each location could be synchronized by using the wave records as references The calibration of the transducer was performed statically This method of calibration was considered to be sufficiently accurate since the transducer has a natural frequency of $10,000 \mathrm{~Hz}$ which is much higher than the input frequencies, and the natural period of the transducer was much shorter than the duration of shock pressure impulse

\section{CHARACTERISTICS OF MODEL WAVES}

Referring to the model set-up as shown in Figure 1, the model wave characteristics are adequately described at the gage location as

$$
\begin{aligned}
\mathrm{H} / \mathrm{L} & =0005 \text { to } 0052 \\
\mathrm{~d} / \mathrm{L}_{\mathrm{o}} & =0027 \text { to } 0111 \\
\mathrm{H} / \mathrm{D}= & 026 \text { to } 118
\end{aligned}
$$

where $H$ is the wave height at the gage location, $d$ is the water depth in the flat channel, $D$ is the tube diameter, $L$ is the wave length in the flat channel, and $L_{0}$ is the equivalent deep water wave length The measured wave heights range from ${ }^{\circ}$ 0131 to 0589 feet and the wave periods range from 173 to 350 seconds Wiegel (Ref 1) suggested that the waves in shoaling water just prior to breaking might be treated as a solitary wave as an approximation Wilson, Webb and Hendricksom (Ref 2) recommended the range of Ursell's parameter $\mathrm{HL}^{2} / \mathrm{d}^{3}$ within which the solitary wave theory is applicable The calculated Ursell's parameters for this study are between 15 and 36 , well within their recommended range of 10 to 40 Therefore, in this study, the solitary wave theory will be used to describe the mode 1 waves measured at the wave gage During the tests, most waves broke on the 115 beach and the locations where white caps were first found as the wave advanced toward the tube were observed and recorded, so that the breaking depth $d_{b}$, measured from the still water level to the beach bottom, can be computed Figure 2 shows the relationships between $\mathrm{H} / \mathrm{T}^{2}$ and $\mathrm{d}_{\mathrm{b}} / \mathrm{T}^{2}$ as compared to the usually referred breaking index curve A surprising result of the wave breaking data was that $\mathrm{H} \approx \mathrm{H}_{\mathrm{b}}$, where $\mathrm{H}_{\mathrm{b}}$ is the wave height at breaking (not measured) Galvin (Ref 3 ) found that

$$
\frac{d_{b}}{H_{b}}=140-685 m
$$

where $m$ is the beach slope 
Using Eq (1), we obtain, for the present slope of $1 / 15$

$$
\frac{H_{b}}{d_{b}}=104
$$

while Figure 2 suggests that $H / d_{h}=11$, confirming the previous statement of $\mathrm{H} \approx \mathrm{H}_{\mathrm{b}}$ The wave forms fit the description of "plunging breakers" by observation Iversen (Ref 4) found that the plunging breakers occurred when $\mathrm{H} / \mathrm{T}^{2}=005$ to 030 for 110 beach slope and $H_{0} / T^{2}=002$ to 020 for 120 beach slope Galvin (Ref 3) defined the occurrence of plunging breakers as

$$
H_{0} / L_{0} m^{2}=09 \text { to } 48
$$

For this study, $\mathrm{H}_{0} / \mathrm{T}^{2}=001$ to 022 and $\mathrm{H} / \mathrm{L}_{\mathrm{o}} \mathrm{m}^{2}=044$ to 88 Reasonable agreement to suggestions by previous investigators was found in defining plunging breakers

\section{TEST RESULTS AND ANALYSIS}

\section{Description of Pressure Time History}

The variation of pressure in time as the plunging breakers passed through the tube structure can best be described by referring to Figure 3 in which the pressure time histories around the tube curcumference are shown for a typical test condition " $\theta$ " values shown in the figure are defined in Figure 7 During the wave uprush, as the wave front contacts the front face of the tube $(\theta=0$ to $\left.90^{\circ}\right)$, pressures of high intensity and short duration were registered at the pount of impact, this pressure will be referred to as "impact pressure", $P_{i}$, throughout this paper Immediately after the impact, the pressures acting upon the front of the tube undergo a smooth continuous variation, normally decreasing in intensity, as the uprushing waves gradually lose their momentum due to the counteracting gravitational force The secondary peak pressure registered immediately after the impact will be designated as $P_{s}$

As a result of wave uprush, a certain volume of water is transported across the crest of the tube The maximum run-up is attained when all the available kinetic energy is converted into potential energy Under the influence of gravity this volume of water flows back across the tube and the wave downrush begins The behavior of reversing flow resembles the case of flow across a spillway, excep that the avallable head decreases with time The pressure time histories recorded on the beach side of the tube $\left(\theta=90^{\circ}\right.$ to $\left.180^{\circ}\right)$ were quite steady during the flow reversing process The reverse flow is suddenly interrupted by the impact accompanying the next onconing wave, and the wave uprush is again repeated In Fig 4, the pressure variation with respect to time is shown for two test cases The times $t=0$ and $t=T$ represent times of two consecutive impacts during which a high pressure intensities were found at the front of the tube for a short duration Therefore, at $t=0$ and $t=T$, the net resultant force on the tube is 
definitely acting shoreward At $t=3 T / 4$, the tube is under the action of reversed flow, the front portion $\left(\theta<90^{\circ}\right)$ of the tube is subjected to pressures less than the hydrostatic pressure at still water level, while the back of the tube $\left(\theta>90^{\circ}\right)$ is subjected to some dynamic pressure in addition to the initial hydrostatic pressure The net resultant force during the wave downrush is thus acting seaward Repetitive wave actions wlll cause the tube to loosen on a beach Additional instantaneous pressure distributions during impact are shown in Fig 5

The Impact Pressure $\mathrm{P}_{i}$

Test results showed that the impact pressure intensity varied with every wave, even though the wave form at the toe of the sloping beach appeared to be rather uniform and periodic Therefore, an appropriate evaluation of the pressure intensity should be based upon a statistical analysis However, the number of waves available to analysis was limited because, after a certain length of time, the wave form became distorted by the reflection from the wave generator Because of this restriction, only eight pressure peaks were averaged, and the dimensionless parameter $\mathrm{P}_{i} / \gamma \mathrm{H}$ is correlated with the wave steepness $\mathrm{H} / \mathrm{L}$ in Fig 6 " $\mathrm{P}_{i}$ " was the pressure difference between the pressure peak measured during the impact and the pressure just prior to the moment of impact The maximum impact occurred as $T=35$ seconds and $H=0282$ feet when the waves broke right in front of the tube The wave steepness for this test case is 001 Fig 6 clearly indicates that steeper waves exert a relatively lower impact as expressed in dimensionless form, because they break at a distance from the tube For the few cases when $H / L<001$, no appreciable breaking of the waves was observed, therefore the impact is relatively low

In the following, an impact-momentum model is postulated to gain further insight to the behavior of impact pressures

Refer to Fig 7 As breakıng waves impinge upon a portion of the tube surface, the normal force exerted on an element of the circumference $\Delta l$ is equal to the rate of change of momentum in the radial direction Thus we may write

$$
-d\left(M_{e} U_{r}\right) / d t=P_{i} \Delta l
$$

where " $M$ " Is the effective mass of the portion of water causing the momentum reaction on the element $\Delta l$ and " $U_{r}$ " is the radial velocity of the mass $M_{e}$ The "-" sign is inserted here to represent a case of decreasing momentum The effective mass $\mathrm{M}_{\mathrm{e}}$ is considered independent of time during the impact when the velocity of the mass is retarded, and may be expressed as

$$
M_{e}=\rho b * \Delta l \cos \alpha
$$

providing that $\Delta l$ is small It is apparently unrealistic to treat the whole horizontal element of width " $b$ " as solid, therefore the effective width is defined as " $b *$ " where $b$ * is much less than b Substituting Eq (4) Into (3), we obtain 


$$
P_{1}=-\rho b * \cos \alpha \frac{d U_{r}}{d t}
$$

If the time variations of " $P_{i}$ " and that of " $\mathrm{U}_{r}$ " are linear, as that assumed by Weggel (Ref 5), then Eq 5 can be integrated as

$$
\int_{0}^{t_{i}} P d t=-\int_{U_{0} \cos \alpha}^{0} \rho b^{*} \cos \alpha d U r
$$

where $t_{i}$ is the duration of impact and $U_{0}$ is the horizontal water particle velocity just before impact (see Figure 7) After integration, we obtain

$$
P_{i}=\rho U_{0}\left(\frac{2 b * \cos ^{2} \alpha}{t_{i}}\right)
$$

or $P_{i}=\rho U_{0} U *$

where $U^{*}$ is a characteristic velocity which has an upper limat equal to the sonic speed in water

Eq (7) is reduced to dimensionless form through the following procedures

(1) The celerity at breaking is computed from solitary wave theory as

$$
c_{b}=\sqrt{g\left(H_{b}+h_{b}\right)}
$$

where $h_{h}$ is the breaking depth measured to the trough of the waves and is related to the still water depth $d_{b}$ as

$$
h_{b}=d_{b}-c_{h} H
$$

where $C_{h}=02$ to 04 from previous experimental studies

(2) Recalling the previous discussion that

$$
\mathrm{H} \approx \mathrm{H}_{\mathrm{b}} \text { and } \frac{\mathrm{d}_{\mathrm{b}}}{\mathrm{H}}=\frac{1}{11}=091 \text {, }
$$

we may write

$$
P_{i} / \gamma H=\left(U_{0} U * / C_{b}^{2}\right)\left(1-C_{h}+d_{b} / H\right)
$$


or

$$
\mathrm{P}_{\mathrm{i}} / \gamma \mathrm{H}=(151 \text { to } 171) \mathrm{U}_{\mathrm{o}} \mathrm{U} * / \mathrm{C}_{\mathrm{b}}^{2}
$$

Referring again to Figure 6 which shows $P_{i} / \gamma \mathrm{H}=19$ when the waves break right in front of the tube $\left(C_{b} \approx U_{o}\right)$, Equation (al)implies

$$
\mathrm{U} * / \mathrm{C}_{\mathrm{b}}=111 \text { to } 126
$$

which shows $U *$ and $C_{b}$ are in the same order of magnitude, much less than the sonic speed in water The impact pressures shown in Figure 6 are much less than those observed by previous investigators who have dealt with wave pressure acting on vertical walls (Ref 6 to 10) The curvature of the tube, which 15 not as conducive to "shock" as plane surfaces, is mainly responsible for the reduction of impact pressure

\section{The Secondary Pressure $P_{s}$}

After the initial impact, a sudden drop of pressure occurs and this pressure is termed "secondary" as was referred to previously The concept of fixed hypothetical mass no longer applies here since there exists a continuous flux of mass toward the tube The kinematics of flow around the tube surface are beyond a theoretical prediction, therefore an accurate estimate of $P$ is difficult to obtain Figure 8 shows the distribution of $\mathrm{P}_{\mathrm{s}} / \gamma \mathrm{H}$ with respect to $\theta$ for different values of $H / D$ For simplicity, if one assumes that the horizontal velocity of water mass in front of the tube remains constant, then the mass flux in the radial direction is $\rho U_{0} \Delta l \cos \alpha$ and the rate of change of momentum in the same direction becomes $\rho U_{0}^{2} \Delta l \cos ^{2} \alpha$, so the application of momentum principle glves

$$
P_{s}=\rho U_{0}^{2} \cos ^{2} \alpha
$$

A similar analysis to that made on the impact pressure gives

$$
P_{s} / \gamma H=\left(U_{o} / C_{b}\right)^{2} \cos ^{2} \alpha\left(1-c_{h}+d_{b} / H\right)
$$

or

$$
\mathrm{P}_{\mathrm{s}} / \gamma \mathrm{H}=(151 \sim 171)\left(\mathrm{U}_{\mathrm{o}} / \mathrm{C}_{\mathrm{b}}\right)^{2} \cos ^{2} \alpha
$$

The upper 1lmit of $\mathrm{P}_{\mathrm{s}} / \mathrm{\gamma H}$ must occur when $\mathrm{U}_{0}=\mathrm{C}_{\mathrm{b}}$, thus

$$
\left(\mathrm{P}_{\mathrm{s}} / \gamma \mathrm{H}\right)_{\max }=(151 \sim 171) \cos ^{2} \alpha
$$


Eq (15) is plotted in Figure 8, the curve is shown to fit the envelope of all data $\mathrm{P}_{\mathrm{S}} / \gamma \mathrm{H}$ decreases as $\mathrm{H} / \mathrm{D}$ increases The trend is reasonable since $\mathrm{U}_{\mathrm{o}} / \mathrm{C}_{\mathrm{b}}$ values are smaller for large $\mathrm{H} / \mathrm{D}$ values, and $\mathrm{Eq}$ (14) shows that " $\mathrm{P}_{\mathrm{s}} / \gamma \mathrm{H}$ is proportional to $\left(\mathrm{U}_{\mathrm{o}} / \mathrm{C}_{\mathrm{b}}\right)^{2}$

\section{Pressures due to Reversed Flow}

During the wave downrush, the flow reverses its direction under the influence of gravitational force The flow patterns resemble those found across a spillway The pressure distribution at the beginning and the end of the reversing flow are shown for six test conditions in Fig 9 At the beginning of wave downrush, the pressure distribution is believed to be hydrostatic since the motion of water particles was negligible at that instant, while at the end of wave downrush, the flow over the tube approaches a steady state so that the pressure distribution on the beach side of the tube $\left(\theta>90^{\circ}\right)$ remains unchanged for a short period of time The overflow along the ocean side of the tube $\left(\theta<90^{\circ}\right)$ is curvilinear with relatively high speed Negative gage pressures were often recorded for $\theta=30^{\circ}$ and $\theta=60^{\circ}$ The total resultant force during the wave downrush is therefore acting seaward, in contrast to the case of wave uprush

\section{SUMMARY AND CONCLUSIONS}

It is found in this study that the uprush of plunging breakers exert little impact on a semi-cylindrical tube as compared to the "shock" pressure caused by waves breaking on a vertical wall The " $\mathrm{P} / \gamma \mathrm{H}$ " value as defined in the paper is at maximum when waves break right in front of the tube (H/L $=0$ 01) Waves steeper than H/L (>0 01) break at a distance away from the tube and the resulting $P_{i} / \gamma H$ decrease as wave steepness increases No noticeable Impact was observed for waves with $\mathrm{H} / \mathrm{L}<001$ An Impulse momentum model gives

$$
P_{1}=\rho U_{0} U *
$$

where

$$
U^{*}=\frac{2 b^{*} \cos ^{2} a}{t_{i}}
$$

and

$$
\mathrm{P}_{i} / \gamma H=(151 \text { to } 171) \mathrm{U}_{\mathrm{o}} \mathrm{U} * / \mathrm{C}_{\mathrm{b}}^{2}
$$

The characteristic velocity $U^{*}$ is in the same order of magnitude as the wave celerity at breaking, $c_{b}$ Therefore, the impact pressure is much lower than the pressure of the water hammer type Detafled characteristics of U* could be studied by fast speed photography along with fast speed pressure recording systems The "secondary pressure" as defined in the paper has a maximum value

$$
\left(\mathrm{P}_{\mathrm{s}} / \gamma H\right)_{\max }=\left(\begin{array}{llll}
1 & 51 \text { to } 171
\end{array}\right) \cos ^{2} \alpha
$$

when $\mathrm{U}_{\mathrm{o}}=\mathrm{C}_{\mathrm{b}}$ 
The above equation represents the envelope of the data $\mathrm{P}_{\mathbf{s}} / \gamma \mathrm{H}$ becomes smaller as $H / D$ increases The validity of the equation

$$
\mathrm{P}_{\mathrm{s}} / \gamma \mathrm{H}=(151 \text { to } 171)\left(\mathrm{U}_{\mathrm{o}} / \mathrm{C}_{\mathrm{b}}\right)^{2} \cos ^{2} \alpha
$$

could be evaluated by measuring $\mathrm{U}_{0}$ During the wave downrush, wave pressures on the beach side of the tube seldomly exceed the net hydrostatic pressure caused by the wave run-up The high speed curvilinear overflow on the ocean side of the tube results in some negative gage pressures so that the resultant force during the wave downrush is acting seaward, in contrast to the case of wave uprush during which the impact force is acting shoreward The oscillatory behavior of the net resultant force creates a stability problem on the structure When designing this type of structure, cut-off walls extending downward into the soil must be provided to resist sliding and overturning of the structure, and also, reducing the uplift pressure on the tube foundation

\section{ACKNOWLEDGEMENTS}

This work was supported in part by the Gray Tech Industries, Incorporated, Mohnton, Pennsylvania Dr $R$ G Dean kindly reviewed the paper and offerred constructive suggestions 
1 Wiege1, R L, Oceanographical Engineering, Prentice-Ha1I, Inc 1964

2 Wilson, B W, Webb, L $M$ and Hendrickson, J A, The Nature of Tsunamis, Their Generation and Dissipation in Water of Finite Depth Natıonal Englneerıng Sclence Company, Technical Report, August, 1962

3 Galvin, C J, Jr , Breaker Travel and Cholce of Design Wave Height, Journal of Waterways and Harbors Div, Proc ASCE, May, 1969

4 Iversen, $H W$, Waves and Breakers in Shoaling Water, Proc Third Conf on Coastal Engineering, 1952, pp 1-12

5 Wegge1, J R and Maxwe11, H C, Numerical Model for Wave Pressure Distributions, Journal of Waterways and Harbors Div, Proc ASCE, August, 1970

6 Wegge1, J R and Maxwe11, H C, Experımental Study of Breaking Wave Pressures, Offshore Technology Conference, Paper No OTC 1244, Apri1, 1970

7 Kame1, A M , Shock Pressure on Coastal Structures, Journal of Waterways, Harbors and Coastal Engineering Div, Proc ASCE, August, 1970

8 Rundgren, L , Water Wave Forces - A Theoretical and Laboratory Study, Bu11 No 54, Institution of Hydraulics, Royal Institute of Technology, Stockholm, Sweden, 1958

9 Ross, C W, Laboratory Study of Shock Pressures of Breaking Waves, Beach Erosion Board Tech Memo No 59, U S Army Corps of Engineers, February, 1955

10 Nagai, S "Shock Pressure Exerted on Breakıng Waves on Breakwaters" Journal of Waterways and Harbors Div , ASCE, Vo1 86, No WW2, Proc Paper 2504, June, 1960 


\section{NOTATION}

The following symbols are used in this paper

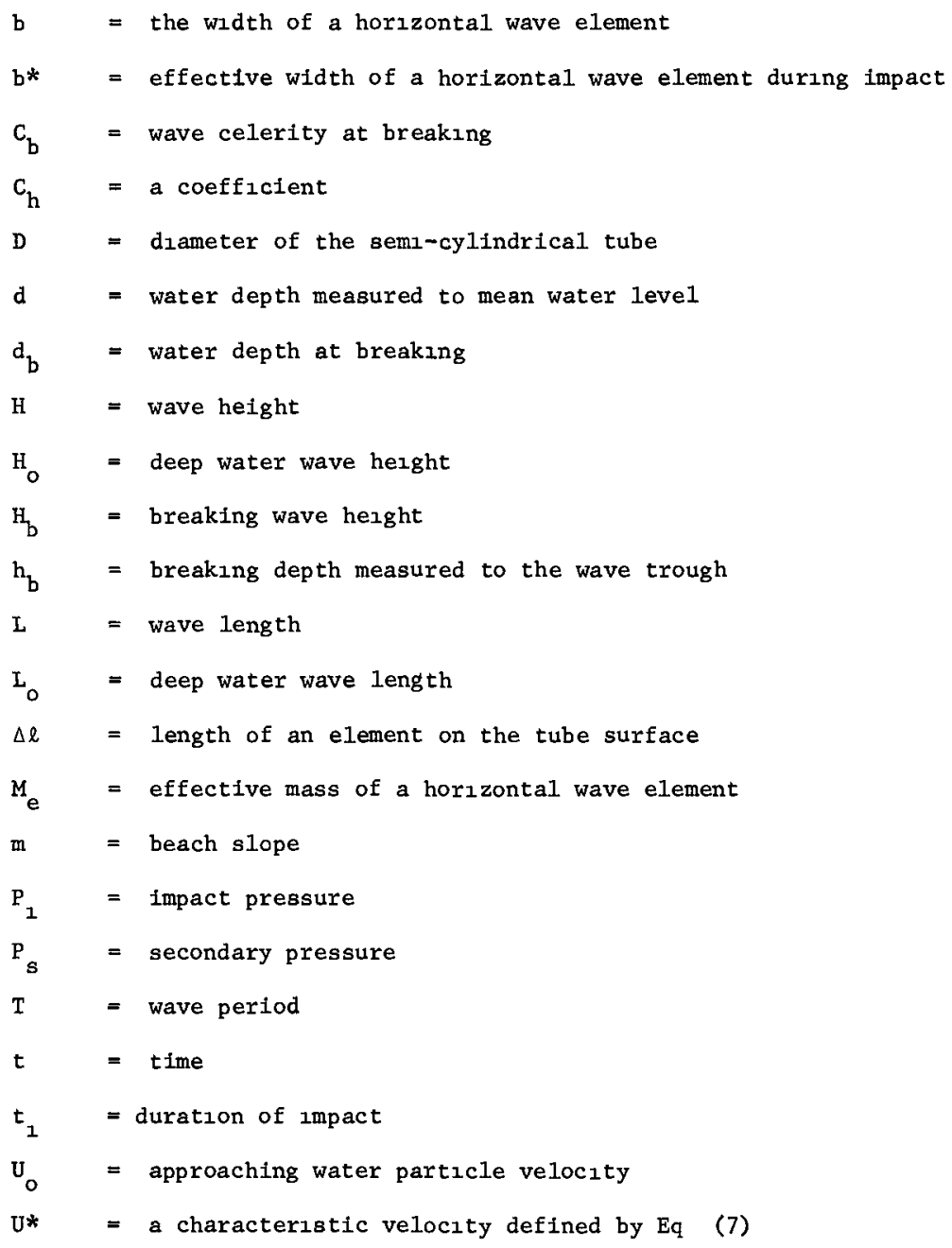




$$
\begin{array}{ll}
U_{r} & =\text { radial velocity component } \\
\rho & =\text { mass density of water } \\
\theta, \alpha & =\text { as defined in Fig } 7 \\
\gamma & =\text { specific density of water }
\end{array}
$$




\title{
LIST OF FIGURES
}

\author{
Figure 1 Model set-up for the pressure test \\ Figure 2 The relationship between $H / T^{2}$ and $d_{b} / T^{2}$ \\ Figure 3 Samples of pressure recordings \\ Figure 4 Typical pressure varlations with respect to time \\ Figure 5 Instantaneous pressure distributions when the pressure \\ intensity at $\theta=0$ is maximum \\ Figure 6 Relationship between dimensionless impact pressure and the \\ wave steepness \\ Figure 7 Wave parameters during impact \\ Figure 8 Distribution of dimensionless secondary pressure around \\ tube surface \\ Figure 9 Pressure variation during wave downrush
}



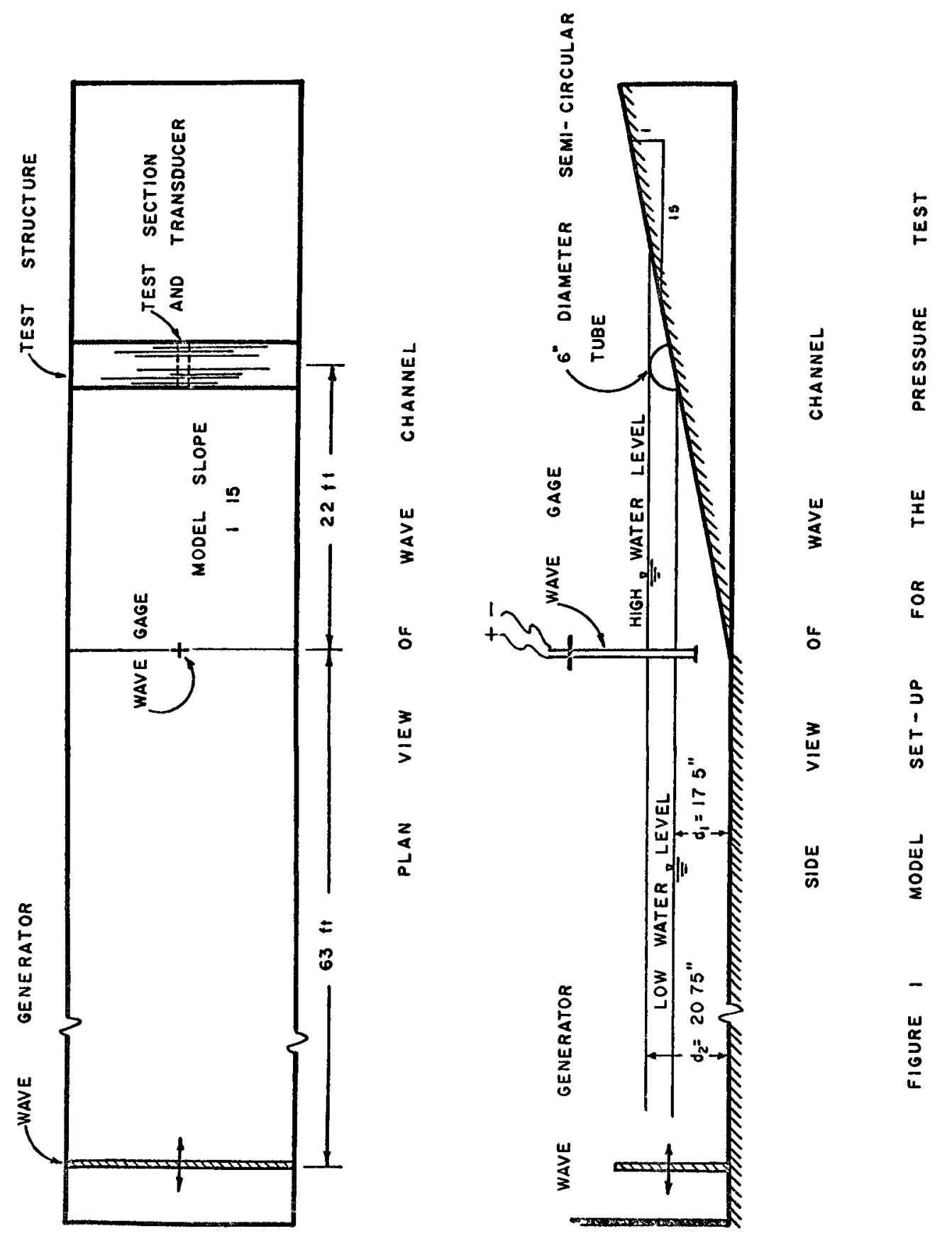


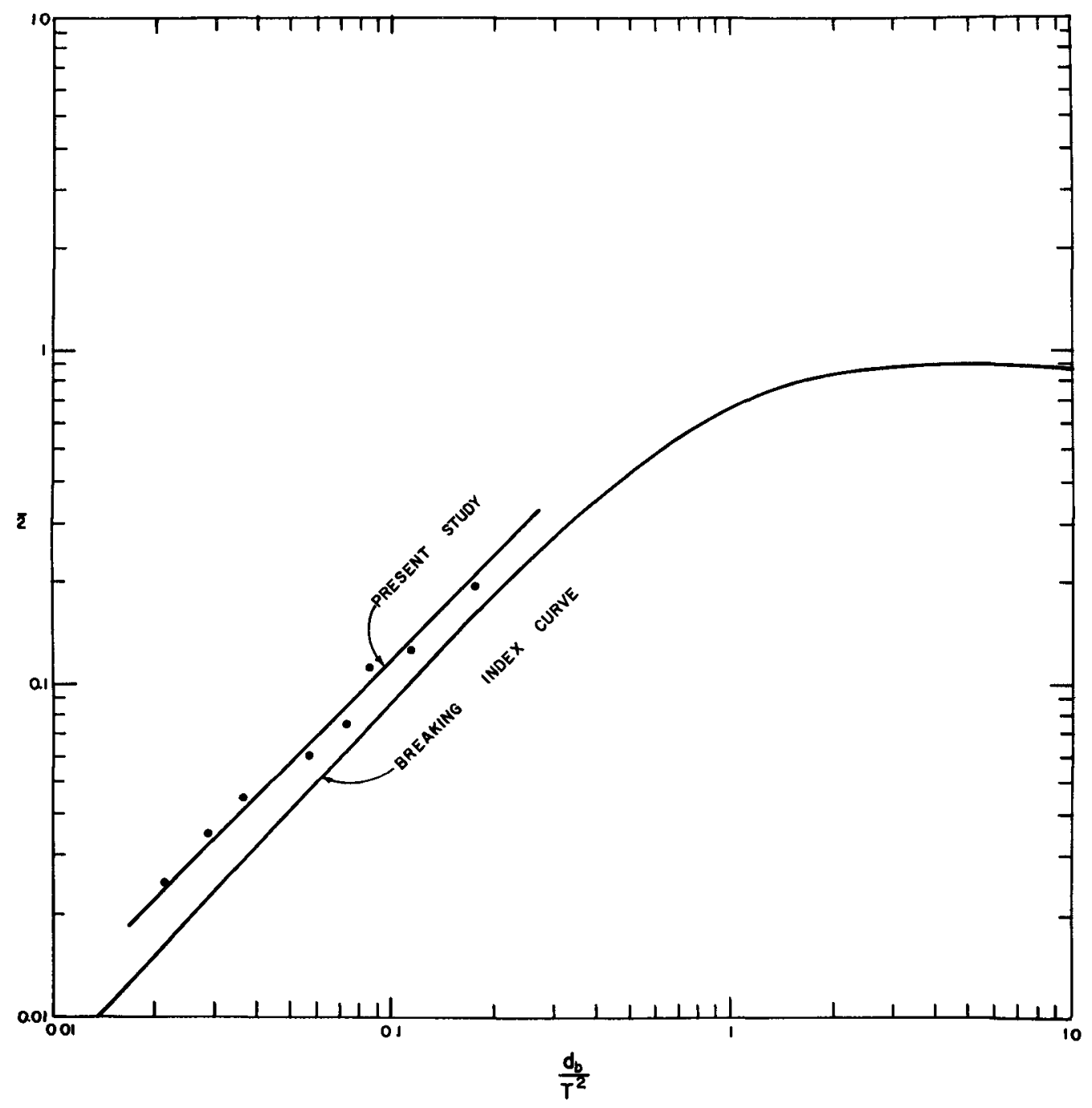

FIGURE 2 RELATIONSHIP BETWEEN $H / T^{2} \& \quad d_{b} / T^{2}$ 
PRESSURE SCALE IN PS I

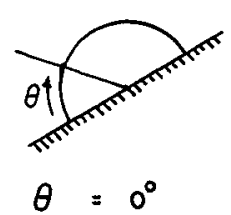

$\theta=30^{\circ}$

$\theta=60^{\circ}$

$\theta=90^{\circ}$

$\theta=120^{\circ}$

$\theta=150^{\circ}$

$\theta=180^{\circ}$

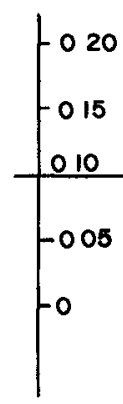

POINT OF IMPACT

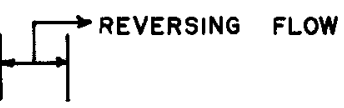

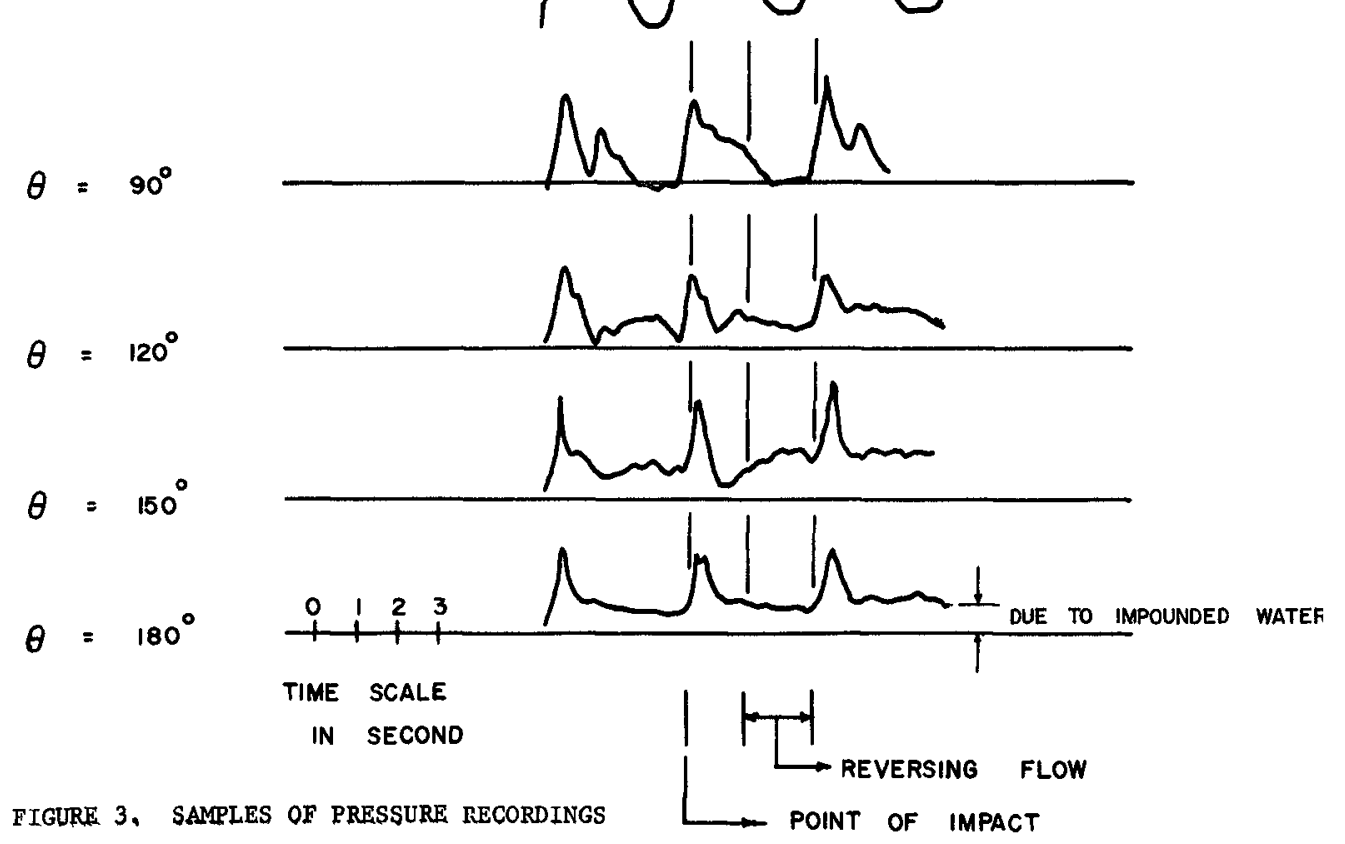


$\theta$

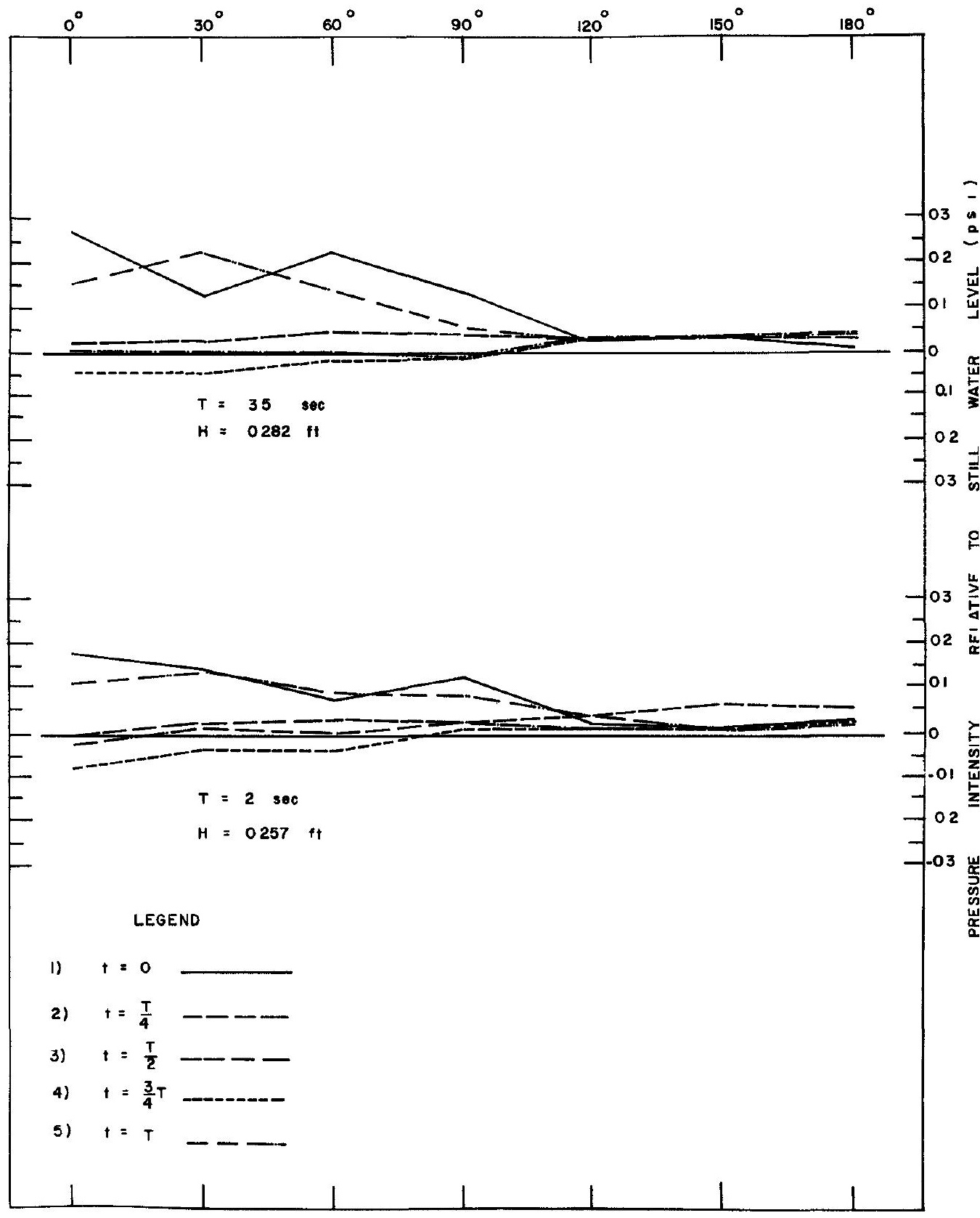

FIGURE 4 TYPICAL PRESSURE VARIATIONS WITH RESPECT TO TIME 


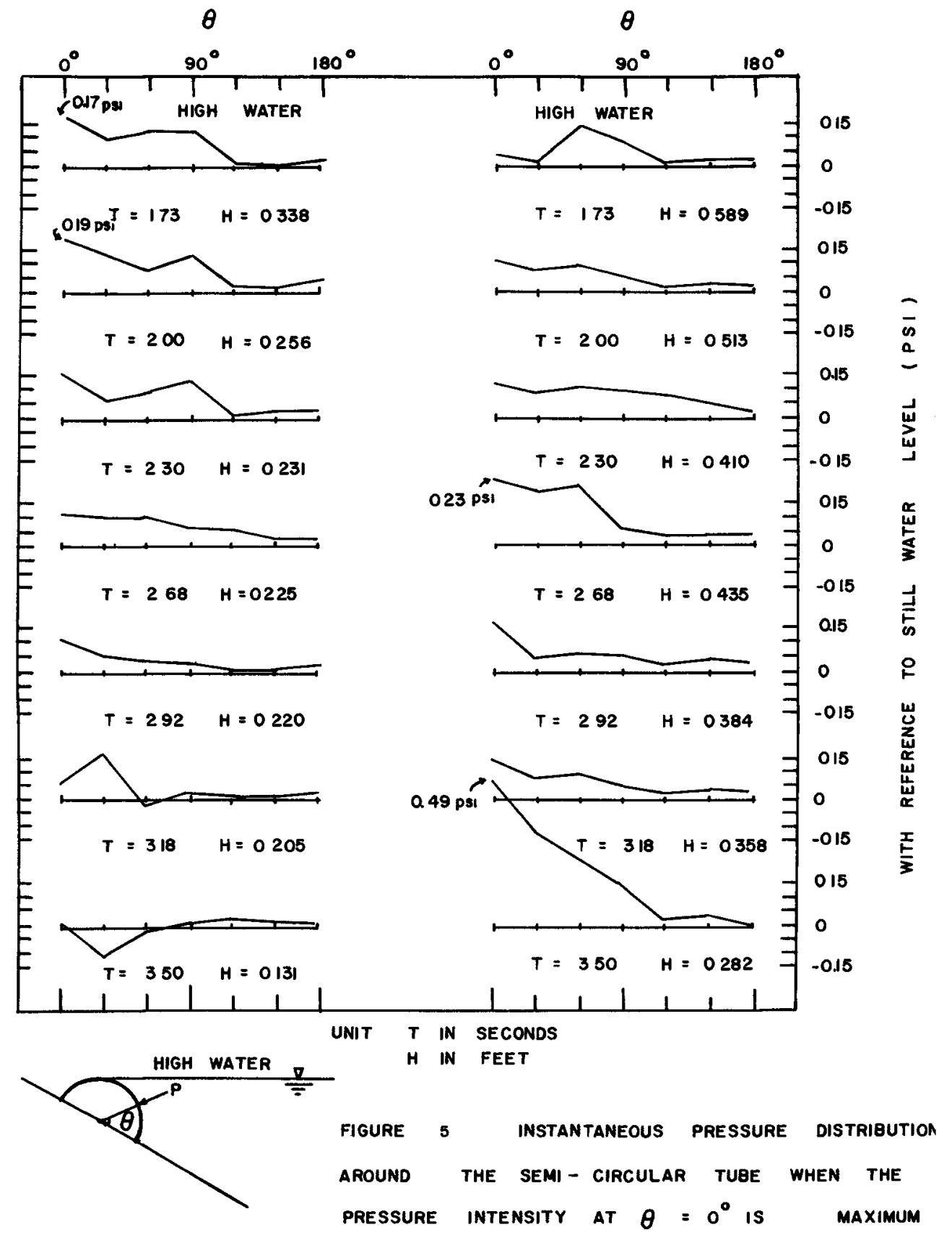




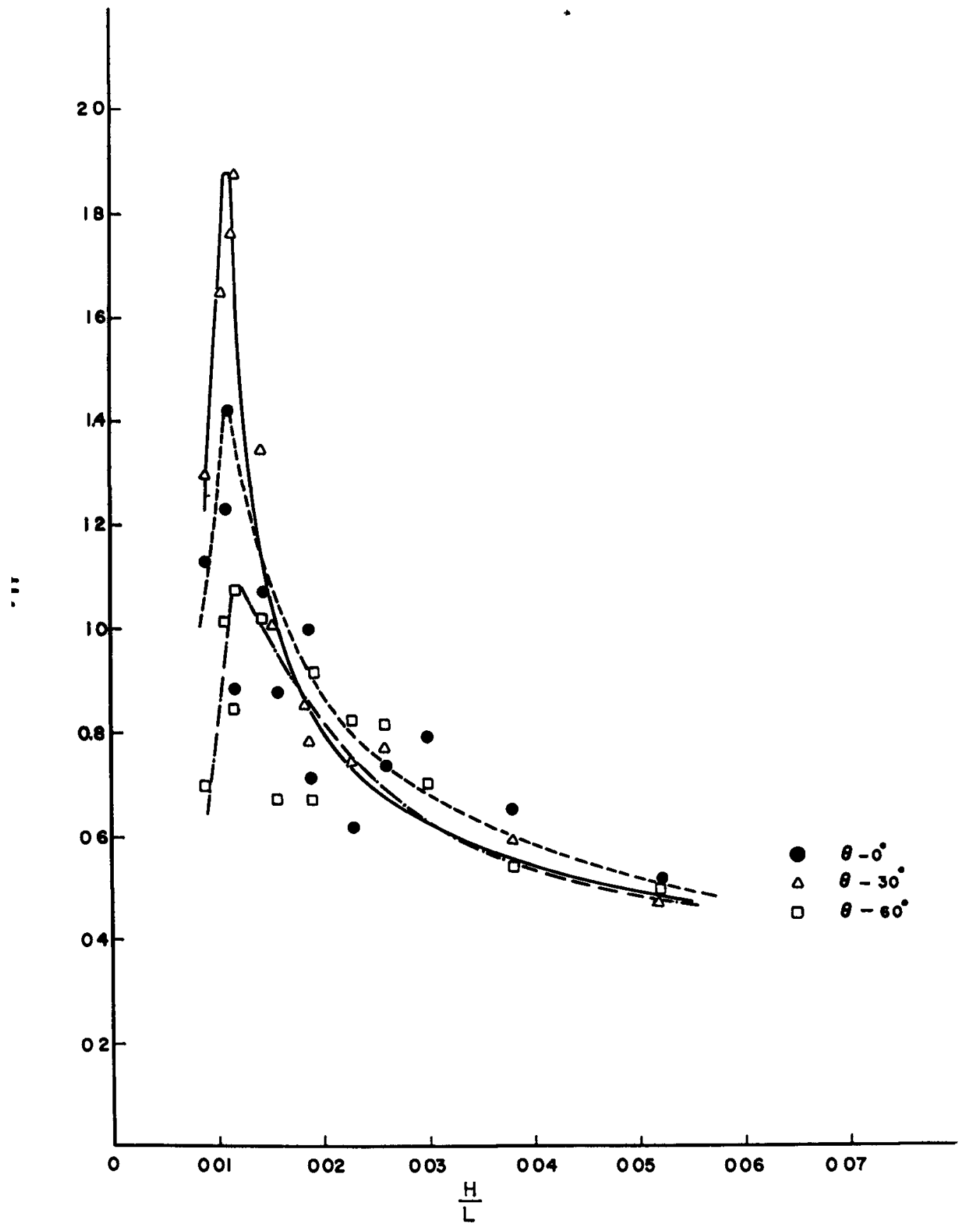

FIGURE 6 RELATIONSHIP BETWEEN DIMENSIONLESS IMPACT PRESSURE AND THE WAVE STEEPNESS 
1488

COASTAL ENGINEERING

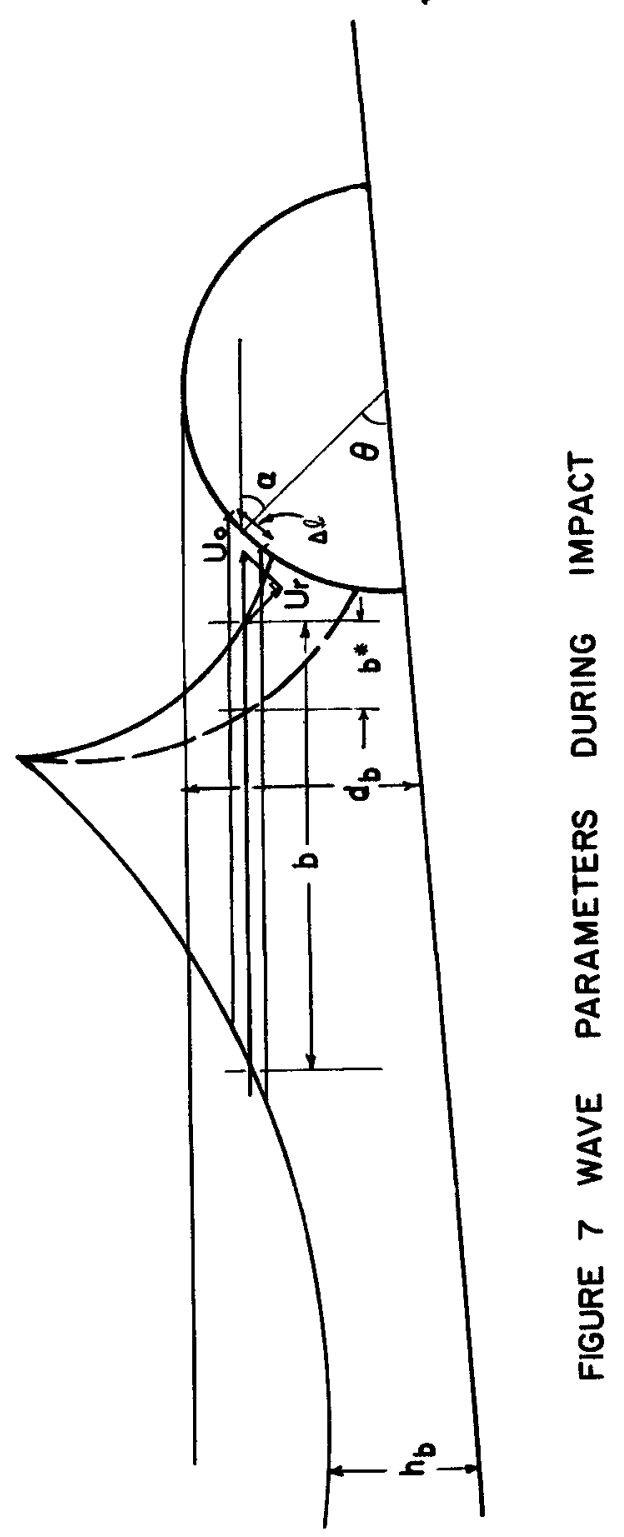




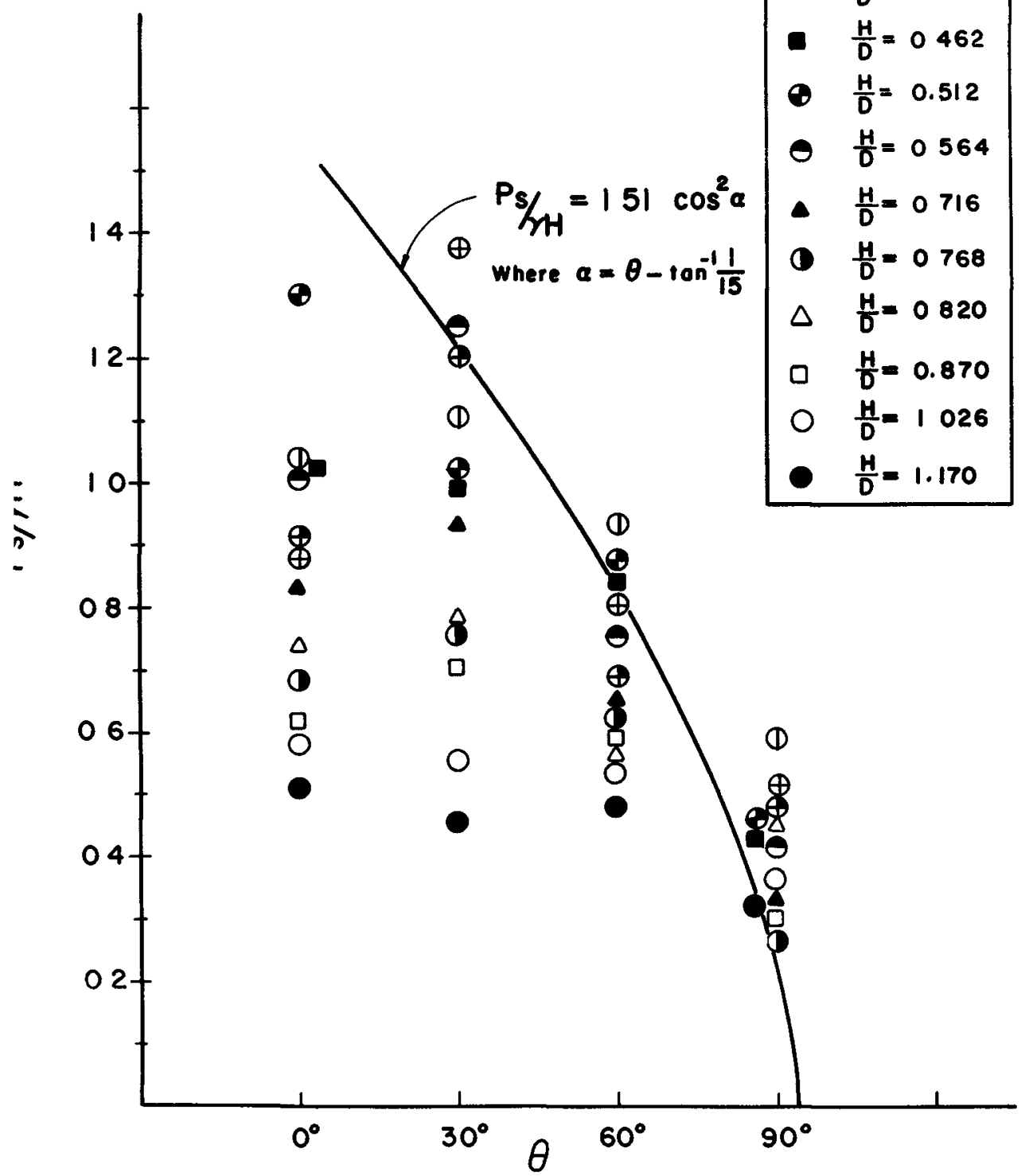

FIGURE 8 DISTRIBUTION OF DIMENSIONLESS SECONDARY PRESSURE AROUND TUBE SURFACE 


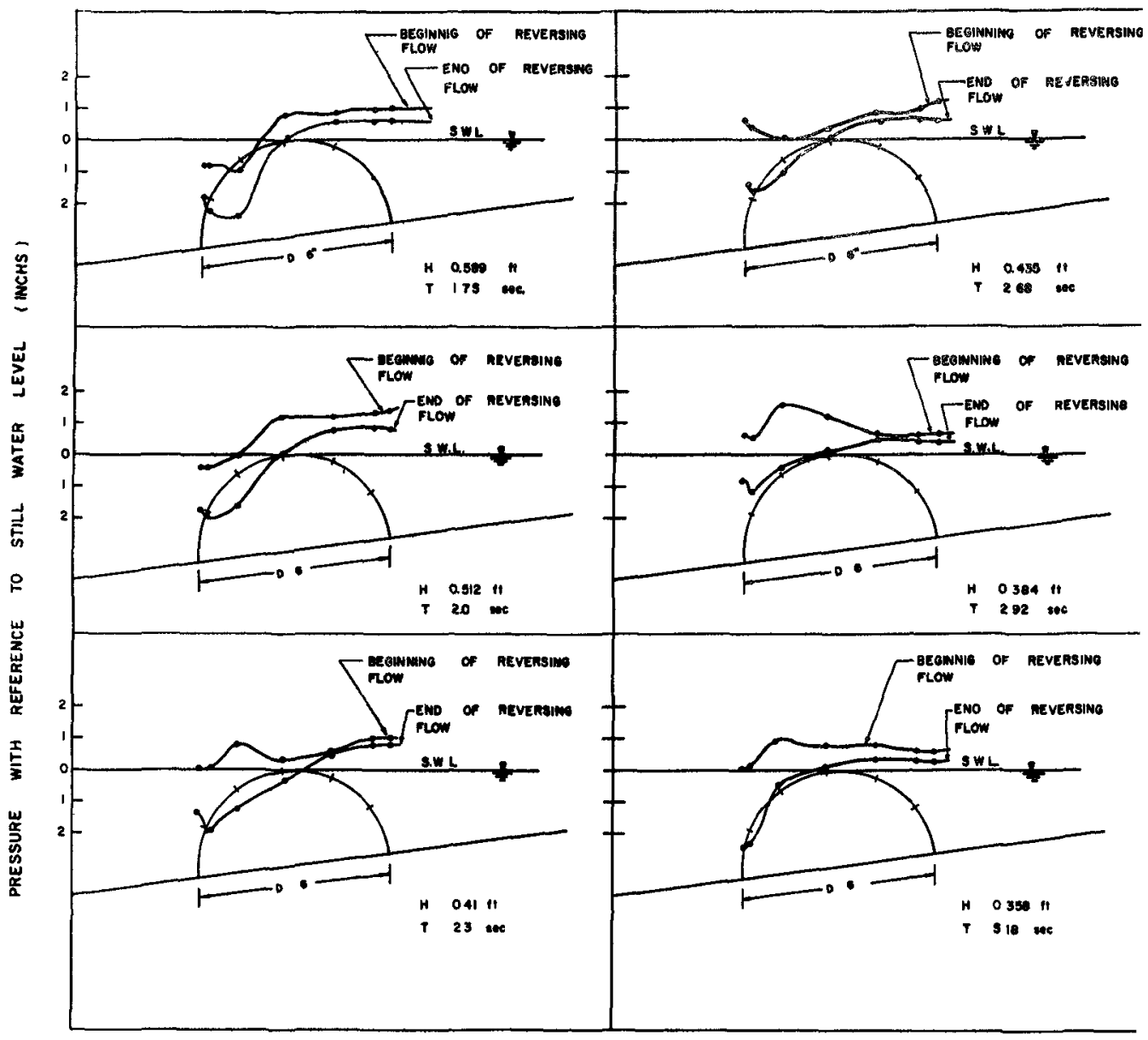

FIGURE 9 PREsSURE VARIATION DURING THE WAVE DOWNRUSH 